\title{
Development of the principles of mathematical modelling and management of behaviour of fine dust fractions of various nature in non-uniform electric field
}

\author{
Maksim Minkin*, and Denis Kuimov \\ Don State Technical University, Chair "Production Process Automation", 344000 Rostov-on-Don \\ Gagarin square 1, Russia
}

\begin{abstract}
The main fundamental objective of this work is the research of behaviour of fine dust fractions (aerosols) of various nature in non-uniform electric field (the crown category) in the conditions of action of electric, gravitational, aerodynamic and other indignations. Determination of the fundamental principles and also development of methods of management of particles of fine fraction with the set physical characteristics will allow to develop adequate mathematical behaviour models of aerosols in nonuniform electric field. In the real work mathematical modelling of electrostatic field in the device is described and the mathematical model is presented. The analysis of physical processes in the device of blocking of dust emissions - "an electrostatic lock" taking into account influence of Aerodynamic effort is carried out from such phenomenon as "Ionic wind".
\end{abstract}

\section{Introduction}

For the solution of an objective application of the means of computer modelling based on application of a finite element method is offered. The mathematical model describing physical processes in an active zone of the electromechanical device of blocking of dust emissions is the cornerstone of computer model. This mathematical model is constructed proceeding from the following regularities. The particle which is non-uniform electric field and under the influence of external indignations is affected by the following forces: 1 . Gravity; 2. Force of action of electric field on charged particle; 3 . Force caused by uneven distribution of electric field strength; 4. Environment resistance force to the movement of particles; 5 . The aerodynamic effort created by "ionic wind".

In the conditions of the crown category the effort from electric field operating on particles of fine fraction is formed under the influence of a volume charge that affects the size of this effort. Also it is necessary to consider the aerodynamic effort convoked by "ionic wind" which in these devices, on the conducted earlier pilot studies makes about 15-20\% of effort, from electric field [1]. Distribution of particles of fine fraction on physical properties and the

\footnotetext{
*Corresponding author: msi 58@mail.ru
} 
sizes also is an important factor as affects dynamics of acquisition of a charge a particle and on aerodynamic properties.

The system of the equations of physical processes of the movement of a particle in nonuniform electric field, generally with any mobile part (an aerosol cloud) is constructed on the basis of earlier developed mathematical model [2,3], however, unlike it, allows to consider influence of the effort operating from "ionic wind".

The numerical solution of this system will allow to predict behaviour of a particle of fine fraction. After obtaining theoretical results for check of their adequacy it is necessary to conduct pilot studies.

The above methodological approaches to carrying out researches, for the solution of the tasks set in the project, are planned to be realized on the basis of specially designed for this purpose experimentally - a laboratory complex. For receiving dust mix the experimental sample of the activator of a vortex layer designed and made in DSTU which allows to make processing of material in the wide range will be used.

\section{Main part}

When giving on a koroniruyushchy electrode of potential of such size at which emergence of the crown category is provided in interelectrode space there are following processes: 1) in the field of space, adjacent to edges or a surface of a koroniruyushchy electrode, the crown cover which is a source of the electrons proceeding from a cover in interelectrode space is formed; 2) the electrons and negatively charged ions proceeding from a crown cover move in the direction of a positively charged form-building electrode and form in interelectrode space a cloud of ions - a volume negative charge; 3 ) at hit in interelectrode space of fine particles of substance on a surface of particles are adsorbed, negatively charged ions and particles of substance get a negative charge; 4) electric field in interelectrode space is created so that: - to provide adsorption with dust particles of a charge; - to reduce the speed of the movement of charged particles.

After hit of a fine particle to the area of diffusion of ions the particle adsorbs on itself a charge. The size of this charge increases in process of advance of a particle in the external area of a crown. At once the effort braking it advance begins to affect it i.e. return of dust particles to the bunker is provided. Dynamics of acquisition of a charge a particle in the course of sedimentation of ions is described by the following expression (formula Potenye) [4-6]:

$$
q(t)=q_{m} \frac{e n_{k} k t}{4 e+e n_{k} k t}
$$

where $e$ - an electron charge; $n_{k}$ - is concentration of ions in the external area of the crown category; $k$-mobility of ions; $t$ - the time spent of a particle in the external area of the crown category; qm is the size of the limit charge acquired by a fine particle:

$$
q_{m}=4 \pi \varepsilon_{0}\left(1+2 \frac{\varepsilon-1}{\varepsilon+2}\right) a^{2} E
$$

here $a$ - the radius of a fine particle; $E$ - electric field strength in a point of finding of a particle; $\varepsilon$ - relative dielectric permeability of material of a particle; $\varepsilon_{0}-$ an electric constant.

Information on distribution of electric field strength in the external area of the crown category obtained by results of modeling of electric field is used when determining mechanical impact on a particle from forces moving a particle, time for which the particle gets a limit charge, and a way which the particle passes during this time. In the devices (electrostatic locks) considered by us the fine particle moves in interelectrode space at the 
expense of the excessive pressure of the air taking place in the bunker with bulk. Then the effort operating on a particle from the air environment will be defined as the work of excessive pressure of air in the bunker or capacity on the cross section of a particle of $F p$. This effort is counteracted by a complex of forces which influence it from electric field in interelectrode space. And, in process of movement of a particle to an exhaust outlet its charge increases and the braking effort while the effort from an air stream can be considered invariable increases. The moment of equilibration of these two efforts will also be the particle stop moment. The lock will be considered executed the functions if the way passed by a particle to a stop is less than a distance from a particle entry point to the external area of the crown category of an exhaust outlet of the bunker to a koroniruyushchy electrode.

One of the main characteristics of interelectrode space of an electrostatic lock is the size and a configuration of field of drift of charged particles from a koroniruyushchy electrode to form-building. In this regard an important indicator is the time spent of a dust particle in the field of drift of charged particles. Increase in the time spent of a dust particle in the field of drift of charges is reached by the rational choice of diameter of form-building electrodes depending on the speed of the movement of a dust stream, the device of various additional form-building electrodes in the form of a grid. Thus, the main condition of functioning of an electrostatic lock is the effective geometry of interelectrode space in which at the movement of a dust particle there are processes above-mentioned earlier. Except a configuration of electric field an important condition of functioning of an electrostatic lock is effective blowing of form-building electrodes. In interelectrode space two processes take place: sedimentation of dust particles on form-building electrodes and braking of dust particles. Blowing performs preventing function to sedimentation of particles on form-building electrodes and their pushing out in a scope of a longitudinal component of electric field. And, an important circumstance is that processes of charging and braking have to happen in the area adjacent to an entrance to interelectrode space, that is it is necessary to exclude a particle run out of those limits where there will be no its full stop. The tool of a research of electric processes in an electrostatic lock is the mathematical model. The analysis of designs of electrostatic locks allows to claim that it is possible to apply assumption about a ploskoparallelnost of electric field in one of sections to a large number of designs, for example, in section the XOY plane. The main section of mathematical model - calculation of an electrostatic lock, makes numerical calculation of electric field a finite element method. The mathematical model has the following appearance [7-10]:

$$
\begin{gathered}
\operatorname{rot} \vec{E}=0 \\
\operatorname{div} \vec{D}=\rho \\
\vec{D}=\varepsilon \vec{E} \\
\overrightarrow{F_{q}}=q \vec{E} \\
F_{\text {п }}=p S \\
q(t)=q_{m} \frac{e n_{0} k t}{4 e_{0}+e n_{0} k t} \\
q_{m}=4 \pi \varepsilon_{0}\left(1+2 \frac{\varepsilon-1}{\varepsilon+2}\right) a^{2} E
\end{gathered}
$$

where $D$ - electric shift; $\rho$ - a volume charge. Let's enter scalar electric potential $\varphi(M)$ on the basis of the first equation of Maxwell: $\operatorname{grad} \varphi(M)=(E)$. Then on the basis of the equations (1), (2) we have $\varphi$ - model of electrostatic field: 


$$
\operatorname{grad} \varphi(M)=-\vec{E}
$$

with boundary conditions

using the following known identities:

$$
\varphi^{(1)}(P)=\varphi^{(0)}(P)=\varphi(P) ; \varepsilon_{1} \frac{\partial \varphi^{(1)}}{\partial n}(P)=\varepsilon_{0} \frac{\partial \varphi^{(0)}}{\partial n}(P)
$$

$$
\begin{gathered}
\operatorname{div}(\varphi \bar{a})=\varphi \operatorname{div} \bar{a}+\bar{a} \operatorname{div} \varphi \\
\iint_{D} \varphi \operatorname{div} \bar{a} d D=\int_{\Gamma} \varphi a_{n} d \Gamma \\
\iiint_{V} \varphi \operatorname{div} \bar{a} d \mathrm{~V}=\iint_{S} \varphi a_{n} d S
\end{gathered}
$$

Basic functions of a triangular element (fig. 3) are determined by the following formulas:

$$
\begin{gathered}
\psi_{i}^{k}(x, y)=\frac{1}{2 S^{k}}\left[\left(x-x_{m}\right)\left(y_{j}-y_{m}\right)-\left(y-y_{m}\right)\left(x_{j}-x_{m}\right)\right] \\
\psi_{i}^{k}(x, y)=\frac{1}{2 S^{k}}\left[\left(x-x_{i}\right)\left(y_{m}-y_{i}\right)-\left(y-y_{m}\right)\left(x_{m}-x_{i}\right)\right] \\
\psi_{m}^{k}(x, y)=\frac{1}{2 S^{k}}\left[\left(x-x_{j}\right)\left(y_{i}-y_{j}\right)-\left(y-y_{j}\right)\left(x_{i}-x_{j}\right)\right]
\end{gathered}
$$

For check of correctness of definition of basic functions of elements equality is used

$$
\psi_{i}^{k}+\psi_{j}^{k}+\psi_{m}^{k}=1 .
$$

Within an element we will approximate required function function

$$
\varphi^{k}=\varphi_{i} \psi_{i}^{k}+\varphi_{j} \psi_{j}^{k}+\varphi_{m} \psi_{m}^{k}
$$

Let's receive the equation for the plane-parallel field:

$$
\varphi^{k}=\varphi_{i} \psi_{i}^{k}+\varphi_{j} \psi_{j}^{k}+\varphi_{m} \psi_{m}^{k}
$$

The decision of the equation was passed by FEM. Two options of FEM are known: projective and variation. In this case the projective option of FEM was used.

\section{Pilot studies}

For the purpose of confirmation of adequacy of a mathematical apparatus of the developed model and correctness of its assumptions experimental check of theoretical results of modeling was executed. Pilot studies of the developed design of the electromechanical device of blocking of dust emissions, in particular cement dust fraction, were carried out in vitro.

On the basis of results of mathematical modeling the plant sample model was developed. For assessment of properties of the developed installation it is necessary to have information on operational characteristics.

The three-dimensional graphic model of the electromechanical device of blocking of dust emissions is given (rice 1) and a design of the device (fig. 2) below. The scheme of pilot studies is submitted on rice 3. For imitation of the changing air stream in system the adjustable fan is installed. Together with air, under the influence of the installed fan, goes to the atmosphere also dust streams. 


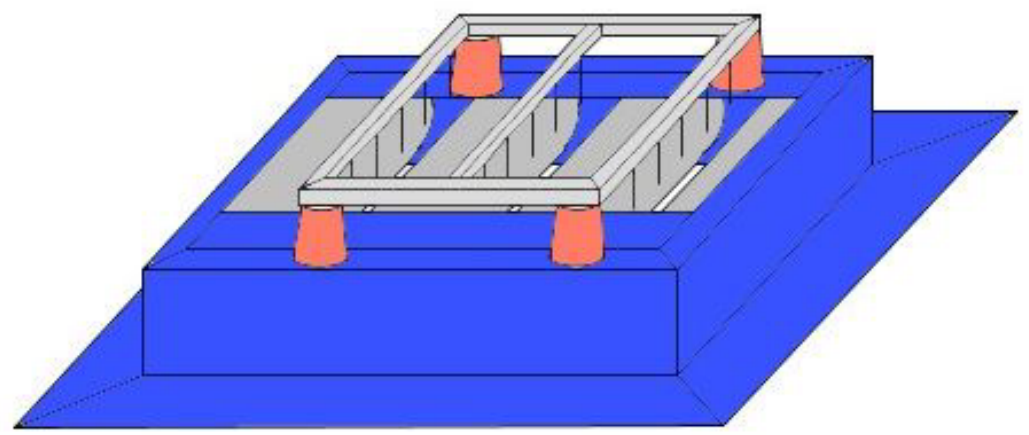

Fig. 1. Three-dimensional graphic model of the electromechanical device of blocking of dust emissions.
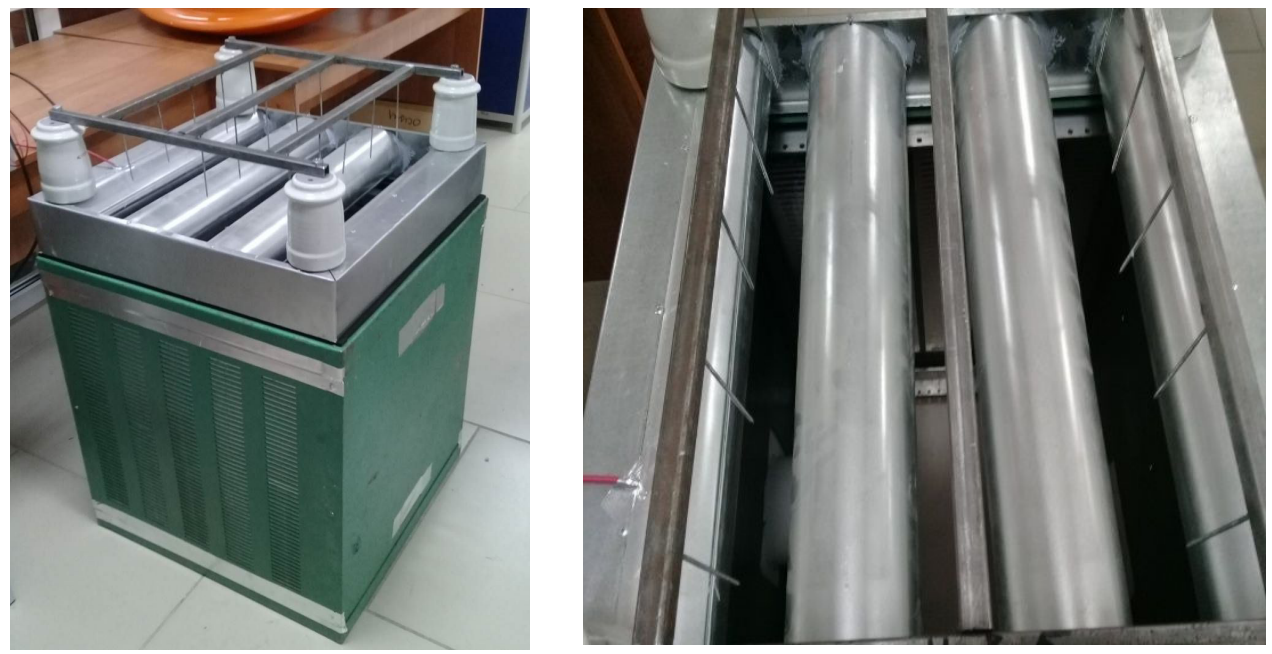

Fig. 2. Experimental sample.

The considered device is the central link of system of blocking of dust streams from the technological systems of the most various productions in the atmosphere. Blocking of dust emissions is provided due to return of moving dust fraction from the air duct in special cameras for collecting dust.

\section{Results}

Table 1. Results of calculations.

\begin{tabular}{|c|c|c|c|c|}
\hline $\begin{array}{c}\text { Speed of a } \\
\text { stream, } \mathrm{m} / \mathrm{s}\end{array}$ & 0,2 & 0,5 & 1 & 1,5 \\
\hline Efficiency, \% & 100 & 100 & 99 & 82 \\
\hline
\end{tabular}


Table 2. Results of measurements on the designed installation of blocking of dust emissions.

\begin{tabular}{|c|c|c|c|}
\hline Parameters & $\begin{array}{c}\text { Unit of } \\
\text { measure }\end{array}$ & $\begin{array}{c}\text { The device is } \\
\text { switched on }\end{array}$ & $\begin{array}{c}\text { The device is } \\
\text { switched off }\end{array}$ \\
\hline $\begin{array}{c}\text { Air temperature in the } \\
\text { place of measurement }\end{array}$ & ${ }^{\circ} \mathrm{C}$ & 38 & 38 \\
\hline $\begin{array}{c}\text { Air speed on emission in } \\
\text { the atmosphere }\end{array}$ & $\mathrm{m} / \mathrm{s}$ & 1,38 & 1,19 \\
\hline $\begin{array}{c}\text { Sampling time } \\
\text { min }\end{array}$ & $\mathrm{m} / \mathrm{c}$ & 370 & 320 \\
\hline $\begin{array}{c}\text { Amount of aspiration air } \\
\text { on emission }\end{array}$ & $\mathrm{mg} / \mathrm{g}^{3}$ & 448,6 & 15,0 \\
\hline $\begin{array}{c}\text { Dust load } \\
\text { Amount of dust in a } \\
\text { stream }\end{array}$ & $\mathrm{g} / \mathrm{s}$ & 0,046 & 0,00134 \\
\hline $\begin{array}{c}\text { Separation efficiency } \\
\text { (n) }\end{array}$ & & - & 97,0 \\
\hline
\end{tabular}

Considering use of the expected results of a research in electromechanical devices of blocking of dust emissions, it is possible to note a number of advantages. It is obvious that the principles which are the cornerstone of operation of these devices allow to expand their scope of application on condition of existence of a method of management of behavior of fine fraction in an active zone of the device and to use electromechanical devices of suppression of dust emissions for allocation of fine fraction with the set properties. Now the most effective way of allocation of fine fraction is electric separation. Rather large number of kinds of the devices intended for division of a stream of fine fraction is known.

On the classification given above the electromechanical device of blocking of fine fraction can be competently as a crown separator. However, the majority of nowadays existing devices of crown separation carry out division of fractions outside area of the crown category that significantly affects their dimensional and power indicators. The electromechanical device of blocking of dust emissions can carry out process of allocation of fraction with the set characteristics directly in the field of the crown category.

On the basis of the carried-out review of domestic and foreign references it is possible to claim, the technique allowing to predict precisely behavior of a particle fine in the field of the crown category taking into account the above described factors does not exist. Without exact forecast of behavior of a particle there is difficult a management of the movement (behavior) of a particle in active area of the electromechanical device of blocking of dust emissions.

\section{References}

1. G.I. Volodin, Electromagnetic processes in devices with any mobile part, Dr. diss., (Novocherkassk, 2009)

2. M.S. Minkin, G.I. Volodin, Research of influence of design data of an electrostatic lock on physical processes in active part (Izv. higher education institutions, Electromecanics, 2013) 
3. M.S. Minkin, Electromechanical devices of blocking of dust emissions, Ph.D. diss., (Novocherkassk, 2013)

4. V.B. Oparin, M.V. Sosnina, K.N Vinogradov, Bulletin of Samara state technical University. Series: Physical and mathematical Sciences, 1 (14), 119 (2007)

5. V.V. Gorbachev, V.E. Litvinov, M.I. Khmelnik, News of higher educational institutions. Problems of printing and publishing, 1, 3 (2002)

6. A.N. Kartashevich, V.A. Belousov, A.V. Kravets, Bulletin of the Belarusian state agricultural Academy, 2, 200 (2018)

7. M.S. Minkin, G.I. Volodin, News of higher educational institutions. Electromecanics, 5, 33 (2013)

8. G.I. Volodin, V.I. Nadtoka, I.I. Nadtoka, V.I. Hludeev, P.F. Sidorenko, V.P. Breslavets, A.Y. Boasters, M.S. Minkin, Patent No.2438794, Russian Federation, MPK B03C3/00

9. G. I. Volodin, V. I. Nadtoka, I.I. Nadtoka, V.P. Breslavets, Nis Ya.Z., P.F. Sidorenko, M. S. Minkin, Patent No.107077, Russian Federation

10. M. S. Minkin, News of higher educational institutions. Electromecanics, 5, 61 (2010) 